\title{
The Machine Learning journal: 25 years young
}

\author{
Peter A. Flach
}

Published online: 12 February 2011

(C) The Author(s) 2011

This issue marks the 25th anniversary of the Machine Learning journal. Volume 1, issue 1 was published in March 1986, under the Executive Editorship of Pat Langley. I am very pleased that Pat agreed to write an editorial for the occasion; you will find his essay on The Changing Science of Machine Learning in the following pages. I urge you to read it, not just to hear about the early years of the journal, ${ }^{1}$ but because it offers a highly pertinent analysis of what machine learning — as a discipline — was, is, and should be. Those who are familiar with Pat and his work will not be surprised to learn that his essay is insightful, entertaining, and, at times, provocative.

You may find something in Langley's essay that you disagree with. Or perhaps your own views are very much aligned with his. In both cases I would like to hear from you. Like any scientific discipline, machine learning thrives on intellectual debate, on the exchange and clash of ideas, and scientific journals are nothing if they don't enable and encourage this. Some might argue that, living as we do in the age of the internet and Web 2.0, of blogging and microblogging, of digital media and Wikipedia, academic journals have lost their importance as vehicles for interaction and discussion. I disagree, because there are several important characteristics that set academic journals apart from other media. In particular, they apply stringent quality control through a well-established peer-review process, and the clear indexing and access mechanism employed ensure that they succeed in achieving longevity as well as reaching a wide audience.

Having said that, I do think that we could do more to make the Machine Learning journal an arena of continuous scholarly debate and not just a container for high-quality but mostly independent research papers. This is high on my list of action items as Editor-in-Chief,

\footnotetext{
${ }^{1}$ Pat denies full responsibility for the colour that has graced the cover of the journal for 25 years, a colour that I have heard being described in somewhat less favourable terms than Pat's 'pea green'. I hope you agree with me that, as of this issue, the cover has become aesthetically more pleasing, without entirely losing the link with the past design.
}

P.A. Flach $(\bowtie)$

Intelligent Systems Laboratory, University of Bristol, Bristol, UK

e-mail: Peter.Flach@bristol.ac.uk 
together with maintaining the high quality and impact of the journal and improving support for the peer-review process. I intend to explore ways to diversify the contents of the journal, and in that context I would welcome more well-argued position papers such as Langley's, with the possibility of publishing them in conjunction with invited responses.

Finally, a word on the papers in this Anniversary issue. None of them was submitted specifically for it, but I chose them from the current Online First pipeline in an attempt to demonstrate the breadth of the discipline as it currently is. I am particularly pleased to see papers spanning more than one area, such as language learning and hyperplanes, or neural networks and relational learning. We also have a Technical Note putting Occam's razor to the test experimentally, with interesting and, perhaps for some, unexpected results. I would like to take this opportunity to emphasise the possibility of submitting Technical Notes to the journal, which are intended to be short, self-contained papers making a single, wellarticulated contribution. It is perhaps of interest for prospective authors to know that this particular Technical Note took less than six months between submission and publication in Online First, and now appears in print within nine months after it was first submitted.

In the coming year we are planning more activities related to the journal's 25 th anniversary, which gives us a good opportunity to look back as well as forward. In the meantime, I hope you enjoy reading this issue, and please do get in touch if you wish to respond to Pat Langley's essay, or if you have ideas about—or want to be involved in—getting a bit more discussion going in the Machine Learning journal.

Editor-in-Chief 